\title{
PENGARUH KEDALAMAN SARANG PENETASAN PENYU HIJAU (Chelonia mydas) TERHADAP MASA INKUBASI DAN PERSENTASE KEBERHASILAN PENETASAN DI PANTAI SUKAMADE, TAMAN NASIONAL MERU BETIRI, BANYUWANGI JAWA TIMUR
}

\author{
EFFECT OF NESTING SITE DEPTH OF GREEN TURTLE (Chelonia mydas) ON THE \\ INCUBATION PERIOD AND HATCHING SUCCESS PERCENTAGE IN SUKAMADE BEACH, \\ MERU BETIRI NATIONAL PARK, BANYUWANGI IN EAST JAVA
}

\author{
Abang Aldhian R. Putera, Laksmi Sulmartiwi dan Wahju Tjahjaningsih \\ Fakultas Perikanan dan Kelautan Universitas Airlangga \\ Kampus C Mulyorejo - Surabaya, 60115 Telp. 031-5911451
}

\begin{abstract}
Indonesia is an archipelago that is rich in diversity of flora and fauna. One of these is a wealth of fauna species of sea turtles. All species of sea turtles in the world by the Convention on International Trade in Endangered Species of Wild Flora and Fauna (CITES) put in Appendix I as endangered and protected and not allowed to be traded. The purpose of this study was to determine effect the ratio of the depth from nest egg incubation and hatching percentage of green turtles (Chelonia mydas) nests at different depths in Sukamade, Betiri Meru National Park, Banyuwangi, East Java.

The design of the study is a randomized block design (RGD). The groups as replicates for RGD, between groups or experimental material media are considered uniform.

The results showed that the average incubation period was $58.87+0.39$ days, then the results were followed by Duncan's multiple range test, which showed that the highest yield obtained by the depth of $50 \mathrm{~cm}$ wasn't significantly different ( $>>0.05$ ) with depth of $30 \mathrm{~cm}$ and $70 \mathrm{~cm}$. While the results obtained at the lowest depth of $90 \mathrm{~cm}$ was significantly different $(\mathrm{p}<0.05)$ with the other depth $(30 \mathrm{~cm}$, $50 \mathrm{~cm}$ and $70 \mathrm{~cm}$ ). While the percentage of hatching success obtained in average hatching was $88.12+$ $0.38 \%$. The Duncan's multiple range test analysis, showed that at a depth of $70 \mathrm{~cm}$ were not significantly different $(\mathrm{p}<0.05)$ from depth of $50 \mathrm{~cm}$, but 70 and $50 \mathrm{~cm}$ depth was significantly different $(\mathrm{p}>0.05)$ from another depth. Whereas the lowest hatching results obtained on depth of $90 \mathrm{~cm}$ are significantly different ( $\mathrm{p}>0.05)$ from the other depth $(30 \mathrm{~cm}, 50 \mathrm{~cm}$ and $70 \mathrm{~cm})$.

The conclusion of this study was different depth of green turtle nests affect the egg incubation period and the percentage of egg hatching success of green turtles.
\end{abstract}

Keywords : green turtle, nest depth, temperature and humidity of the sand

\section{Pendahuluan}

Indonesia merupakan negara kepulauan yang kaya akan keanekaragaman flora dan fauna. Salah satu dari kekayaan fauna tersebut adalah spesies penyu laut. Di Indonesia perlindungan terhadap semua jenis penyu laut telah ditetapkan di dalam Undang-Undang Republik Indonesia No. 5 Tahun 1990 dan dipertegas dengan Peraturan Pemerintah RI No. 7 Tahun 1999 tentang Pengawetan Jenis-jenis Tumbuhan dan Satwa yang Dilindungi. Dalam peraturan pemerintah tersebut ditetapkan semua jenis penyu dilindungi (Purwanasari, 2006).

Secara umum, Purwanasari (2006) menyatakan bahwa, penyebab penurunan populasi penyu hijau di alam dapat dikelompokkan menjadi dua faktor, yaitu; faktor alam dan faktor anthropogenic. Faktor alam berhubungan dengan perubahan lingkungan yang terjadi secara alamiah, seperti; abrasi pantai, perubahan suhu pasir, penyakit dan predator alami. Faktor anthropogenic merupakan ancaman yang berhubungan dengan adanya aktifitas manusia, baik pemanfaatan terhadap pantai habitat peneluran maupun pemanfaatan terhadap spesies penyu, misalnya; pemanfaatan penyu dan telur penyu serta interaksi terhadap aktifitas perikanan.

Tujuan dari penelitian ini adalah untuk mengetahui perbandingan masa inkubasi telur dan persentase penetasan penyu hijau ( $C$. mydas) pada kedalaman berbeda di Pantai Sukamade, Taman Nasional Meru Betiri, Banyuwangi, Jawa Timur.

Pantai Sukamade, Taman Nasional Meru Betiri, Banyuwangi Jawa Timur adalah salah satu UPTD milik pemerintah di bawah naungan Dinas Kehutanan Provinsi Jawa Timur 
merupakan salah satu tempat yang sudah ditetapkan sebagai kawasan perlindungan terhadap populasi penyu hijau (C. mydas) dimana tingkat pendaratan induk untuk bertelur masih memiliki tingkat kestabilan yang tinggi karena pengelolaan wilayah yang tetap alami dipilih dalam pelaksanaan penelitian ini.

\section{Materi dan Metode}

Penelitian ini dilaksanakan pada bulan 21 Mei 2011 sampai dengan 14 Agustus 2011 di Pantai Sukamade, Dusun Sukamade, Taman Nasional Meru Betiri, Banyuwangi, Jawa Timur. Metode yang digunakan dalam penelitian ini adalah metode eksperimental.

Materi penelitian terdiri dari alat dan bahan penelitian. Bahan yang digunakan dalam penelitian ini adalah 480 butir telur penyu hijau (C. mydas) dengan ukuran garis tengah $42-46$ $\mathrm{mm}$ yang baru dikeluarkan dari tubuh induknya dan diambil dari sarang alami telur penyu hijau di pantai peneluran Sukamade. Media yang digunakan adalah pasir di lokasi penetasan telur. Alat yang digunakan di dalam penelitian ini meliputi; termometer dengan skala Celcius untuk mengukur suhu sarang dan lingkungan penetasan telur, meteran untuk mengukur kedalaman sarang, soil test untuk mengukur kelembaban sarang, sekop untuk pembuatan sarang, ember plastik dengan diameter $30 \mathrm{~cm}$ untuk pemindahan telur ke sarang semi alami, kayu dan plat seng untuk pemberian label (tanda) sarang penelitian, pipa paralon untuk tempat termometer pada saat pengukuran suhu dan kelembaban sarang, serta jangka sorong atau calipper dengan akurasi setebal $0,05 \mathrm{~mm}$ untuk mengukur diameter telur penyu hijau.

Rancangan penelitian yang digunakan adalah Rancangan Acak Kelompok (RAK) (Kusriningrum, 2008), sebab penelitian ini memiliki dua sumber keragaman yaitu perlakuan dan media atau bahan percobaan disamping pengaruh acak. Kelompok sebagai ulangan untuk RAK, antar kelompok media atau bahan percobaan tersebut dianggap seragam. Perlakuan kedalaman sarang penetasan pada penelitian utama dengan ulangan sebanyak 6 kali.

\section{Hasil dan Pembahasan}

Data masa inkubasi telur diperoleh setelah menghitung hari dari awal oviposisi sampai dengan munculnya tukik penyu hijau ke permukaan sarang, sedangkan data keberhasilan penetasan telur diperoleh setelah dilakukan pembongkaran sarang penetasan telur penyu hijau pada hari ke 65. Data masa inkubasi diperoleh yaitu dengan menghitung selang waktu antara oviposisi sampai dengan munculnya sebagian besar tukik hasil penetasan di permukaan sarang perlakuan. Oviposisi telur merupakan waktu peletakan telur pada sarang perlakuan yang telah dipersiapkan (Ariane, 1994).

Hasil analisis data menggunakan ANOVA, menunjukkan bahwa perlakuan kedalaman sarang penetasan berpengaruh nyata $(\mathrm{p}<0,05)$ terhadap masa inkubasi telur penyu hijau. Hasil tersebut dilanjutkan dengan uji jarak berganda Duncan, yang menunjukkan bahwa hasil tertinggi diperoleh kedalaman 50 $\mathrm{cm}$ tidak berbeda nyata $(\mathrm{p}>0,05)$ dengan kedalaman $30 \mathrm{~cm}$ dan $70 \mathrm{~cm}$. Hasil terendah didapat pada kedalaman $90 \mathrm{~cm}$ berbeda nyata $(\mathrm{p}<0,05)$ dengan kedalaman lain $(30 \mathrm{~cm}, 50 \mathrm{~cm}$, dan $70 \mathrm{~cm})$.

Analisis data dilakukan dengan cara menghitung jumlah telur yang menetas dari jumlah telur yang diletakkan pada tiap sarang perlakuan, kemudian data dikonversikan ke dalam bentuk persen. Hasil analisis data menggunakan ANOVA, menunjukkan bahwa perlakuan kedalaman sarang penetasan berpengaruh nyata $(\mathrm{p}<0,05)$ terhadap keberhasilan penetasan telur penyu hijau. Hasil tersebut dilanjutkan dengan uji jarak berganda Duncan, bahwa pada kedalaman $70 \mathrm{~cm}$ tidak berbeda nyata $(p<0,05)$ dengan kedalaman 50 $\mathrm{cm}$, akan tetapi kedalaman 70 dan $50 \mathrm{~cm}$ berbeda nyata $(p>0,05)$ dengan kedalaman 30 $\mathrm{cm}$ dan $90 \mathrm{~cm}$. Hasil penetasan yang terendah didapat pada kedalaman $90 \mathrm{~cm}$ yang berbeda nyata $(\mathrm{p}>0,05)$ dengan kedalaman yang lain (30 $\mathrm{cm}, 50 \mathrm{~cm}$, dan $70 \mathrm{~cm}$ ).

Hasil pengujian masa inkubasi telur dengan kedalaman yang berbeda, didapatkan bahwa kedalaman $30 \mathrm{~cm}, 50 \mathrm{~cm}$, dan $70 \mathrm{~cm}$ tidak berbeda nyata $(\mathrm{p}<0,05)$, dimana rata-rata masa inkubasi penetasan pada kedalaman 30 $\mathrm{cm}, 50 \mathrm{~cm}$, dan $70 \mathrm{~cm}$ antara 57 - 58 hari. Penetasan pada kedalaman $90 \mathrm{~cm}$ berbeda nyata ( $p>0,05)$ dengan kedalaman $30 \mathrm{~cm}, 50 \mathrm{~cm}$, dan $70 \mathrm{~cm}$ yaitu diperoleh masa inkubasi pada kedalaman $90 \mathrm{~cm}$ selama 62 hari. Masa inkubasi sangat dipengaruhi oleh suhu pasir dan kelembaban pasir. Miller (1999) dalam Satriadi dkk. (2004) menyatakan bahwa suhu berpengaruh terbalik dengan masa inkubasi. Telur-telur penyu yang diinkubasi pada suhu kurang dari $23^{0} \mathrm{C}$ pada masa terakhir inkubasinya, hanya sedikit yang menetas, sedangkan telur-telur yang diinkubasi lebih dari $33^{\circ} \mathrm{C}$ tidak ada yang menetas. Dalam kisaran suhu $26^{\circ} \mathrm{C}-32^{\circ} \mathrm{C}$, perubahan $1{ }^{\circ} \mathrm{C}$ akan menambah atau mengurangi masa inkubasi selama 5 hari. Suhu sarang juga mempengaruhi 
perkembangan dan metabolisme embrio, karena perkembangan dan metabolisme embrio akan terganggu apabila suhu sarang melebihi kisaran normal, yaitu $24^{0} \mathrm{C}-34^{0} \mathrm{C}$.

Schulz (1975), Nuitja (1983) dalam Ariane (1994) mengungkapkan bahwa suhu sarang dan kelembaban pasir sarang penetasan telur penyu hijau dipengaruhi oleh kedalaman, karena semakin dalam sarang, suhu di dalamnya makin stabil. Lebih lanjut Nuitja (1983) mengungkapkan bahwa masa inkubasi telur penyu hijau yang ditetapkan secara alamiah adalah 54 - 61 hari, sedangkan masa inkubasi di dalam sarang buatan (styrofoam box) selama 73 hari.

Berdasarkan hasil penelitian telur penyu hijau pada kedalaman berbeda $(30 \mathrm{~cm}$, $50 \mathrm{~cm}, 70 \mathrm{~cm}$ dan $90 \mathrm{~cm}$ ) didapatkan bahwa kedalaman $70 \mathrm{~cm}$ memiliki persentase penetasan tertinggi $(97,50 \%)$ yang tidak berbeda nyata $(\mathrm{p}<0,05)$ dengan kedalaman $50 \mathrm{~cm}$ $(95,83 \%)$. Perlakuan dengan laju penetasan terendah terdapat pada kedalaman $90 \mathrm{~cm}$ $(73,33 \%)$. Hal ini disebabkan pada kedalaman $50 \mathrm{~cm}$ dan $70 \mathrm{~cm}$, sarang penetasan masih termasuk ke dalam range laju penetasan yang tinggi. Merwe (2006) menjelaskan bahwa kedalaman $50 \mathrm{~cm}$ dan $75 \mathrm{~cm}$ merupakan kedalaman terbaik untuk sarang penetasan penyu hijau. Hal ini disebabkan oleh dua faktor penting yaitu tingkat kestabilan suhu atau temperatur pasir $\left(29,8^{\circ} \mathrm{C}-31,2^{\circ} \mathrm{C}\right)$ dan kelembaban pasir sarang $(37,50 \%-56,25 \%)$ pada kedalaman tersebut.

Mrosovsky (1994), Broderick et al. (2000) dalam Merwe (2006) mengungkapkan bahwa kedalaman sarang dapat mempengaruhi suhu sarang, sehingga sarang menjadi stabil. Dari data hasil penelitian, dapat dilihat bahwa pada kedalaman $30 \mathrm{~cm}$ memiliki tingkat kestabilan suhu yang sangat rendah dan memiliki persentase penetasan yang rendah juga yaitu $85,85 \%$. Suhu sarang pada kedalaman 30 $\mathrm{cm}$ fluktuatif $\left(29,7^{0} \mathrm{C}-32,1^{\circ} \mathrm{C}\right)$, karena kedalaman sarang memiliki jarak yang cukup dekat dengan permukaan pasir sarang sehingga proses konveksi radiasi sinar matahari dari luar langsung mempengaruhi kestabilan suhu dalam pasir sarang. Satriadi dkk. (2004) menjelaskan bahwa fluktuasi suhu dalam sarang penetasan telur penyu hijau memberikan pengaruh langsung pada kelembaban sarang penetasan. Kelembaban sarang memberikan pengaruh besar terhadap penetasan telur, karena kelembaban yang terlalu rendah dan kelembaban pasir yang terlalu tinggi dapat menyebabkan pembusukan pada telur penyu hijau. Lebih lanjut Solomon dan Baird (1980) dalam Satriadi dkk. (2004) menjelaskan bahwa lingkungan yang memiliki tingkat kelembaban rendah memiliki persentase kematian lebih tinggi, karena telur penyu sangat sensitif terhadap kekeringan. Telur-telur penyu mengalami penyerapan dan pertukaran air selama masa inkubasi, sehingga volumenya lebih besar. Sebaliknya, kelembaban yang tinggi pada sarang dapat mengakibatkan tumbuhnya jamur pada kulit telur dan masuknya bakteri sehingga menghambat pertukaran gas dalam sarang. Kelembaban sarang perlakuan pada kedalaman $30 \mathrm{~cm}$ mengalami fluktuatif $(16,25 \%$ - 27,50\%) dimana kelembaban sarang pada kedalaman ini sangat dipengaruhi oleh curah hujan yaitu sebesar 238,53 mm. Pada curah hujan tinggi, kelembaban menjadi meningkat karena terjadi absorbsi (penyerapan) air ke dalam pasir.

Faktor lain yang menentukan keberhasilan penetasan telur adalah ukuran butir pasir, dimana persentase ukuran pasir (x) pantai Sukamade didominasi ukuran sedang, yaitu 0,22 $\mathrm{mm}<\mathrm{x}<1 \mathrm{~mm}$ berkisar antara $49-95,5 \%$ dengan jenis pasir adalah pasir kwarsa. Yustina., dkk (2004) mengatakan nilai mean size $(\mathrm{Mz})$ pasir dapat diklasifikasikan sebagai berikut: (1) pasir kasar (coarse sand) mempunyai diameter ukuran butiran pasir $>0,4$ $\mathrm{mm},(2)$ pasir menengah/ sedang (medium sand) berukuran $0,25 \mathrm{~mm}<\mathrm{x}<0,4 \mathrm{~mm}$, (3) pasir halus (fine sand) berukuran $0,1 \mathrm{~mm}<\mathrm{x}<0,24 \mathrm{~mm}$, dan (4) pasir sangat halus (veryfine sand) berukuran $<0,1 \mathrm{~mm}$.

Diameter ukuran butiran pasir sedang pada pantai Sukamade dapat diartikan bahwa pasir pantai Sukamade termasuk pasir yang dapat mengalirkan air dan menampung air pada sarang penetasan karena pasir bertekstur sedang memiliki pori yang tidak terlalu besar sehingga dapat menstabilkan suhu dan kelembaban sarang penetasan. Menurut Nuitja (1992) dalam Ariane (1994) pasir berukuran sedang sesuai untuk habitat peneluran penyu. Mulyani (2006) menyatakan bahwa ukuran butiran pasir yang dominan pada penetasan alami adalah dengan diameter $0,25 \mathrm{~mm}<\mathrm{x}<0,4 \mathrm{~mm}$ yang termasuk pasir sedang, sedangkan pada sarang buatan adalah pasir dengan ukuran diameter 0,1 $\mathrm{mm}<\mathrm{x}<0,24 \mathrm{~mm}$ yang termasuk pasir halus. Ukuran pasir yang lebih halus akan menyerap dan melepaskan panas lebih lambat. Nybakken (1992) dan Ackerman (1997) dalam Satriadi dkk. (2004) menyatakan bahwa pasir yang bertekstur kasar bersifat lebih mengalirkan air daripada menampung air karena pasir bertekstur kasar memiliki pori-pori yang lebih besar. Hal ini dapat menyebabkan sarang penetasan 
memiliki tingkat kelembaban yang rendah, padahal telur penyu membutuhkan kadar air yang cukup $(4-6 \%)$ selama masa inkubasi karena telur melakukan penyerapan dan pertukaran air dalam perkembangan embrionya (Satriadi, dkk. 2004).

Pada kedalaman $90 \mathrm{~cm}$, derajat penetasan telur penyu hijau yaitu sebesar $73,33 \%$. Rendahnya derajat penetasan telur ini disebabkan karena suhu yang terlalu rendah pada pasir sarang penetasan telur. Selain itu, pasir sarang penetasan pada kedalaman $90 \mathrm{~cm}$ memiliki kelembaban yang cukup tinggi yaitu $76,25 \%$ - 81,25\% sehingga berpengaruh langsung pada penetasan telur. Stancyk dan Ross (1978) dalam Satriadi dkk. (2004) mengungkapkan bahwa kelembaban pasir yang terlalu tinggi dapat membusukkan telur-telur penyu. Penyebab lain rendahnya derajat penetasan telur penyu hijau pada kedalaman 90 $\mathrm{cm}$ adalah kedalaman yang terlalu dalam, sehingga banyak tukik penyu yang tidak bisa mencapai permukaan pasir ketika menetas sehingga menyebabkan banyak tukik mati.

\section{Kesimpulan}

Kedalaman sarang penetasan telur penyu hijau yang berbeda memberikan pengaruh terhadap masa inkubasi telur. Masa inkubasi untuk penetasan telur penyu hijau yang paling optimum yaitu 58 hari didapat pada kedalaman $70 \mathrm{~cm}$ dari permukaan pasir. Kedalaman sarang penetasan telur penyu hijau yang berbeda memberikan pengaruh terhadap tingkat keberhasilan penetasan telur penyu hijau. Tingkat persentase keberhasilan penetasan terbaik yaitu $97,50 \%$ didapat pada kedalaman $70 \mathrm{~cm}$ dari permukaan pasir. Sebaiknya kedalaman sarang penetasan semi alami yang terdapat di Pantai Sukamade, Taman Nasional Meru Betiri menggunakan kedalaman $50 \mathrm{~cm}-70 \mathrm{~cm}$ pada sarang penetasan semi alaminya untuk meningkatkan derajat penetasan.

\section{Daftar Pustaka}

Ariane, I. 1994. Studi Masa Inkubasi dan Keberhasilan Penetasan Semi Alami Telur Penyu Hijau (Chelonia mydas) di Pantai Sukamade, Taman Nasional Meru Betiri. Skripsi. Jurusan Biologi, Fakultas Matematika dan Ilmu Pengetahuan Alam, Universitas Airlangga. Surabaya. Hal. 4-24

Kusriningrum, R.S. 2008. Perancangan Percobaan. Fakultas Kedokteran Hewan, Universitas Airlangga.
Airlangga University Press. Surabaya. Hal 5-69.

Merwe, V. D, Jason; Ibrahim, Kamarruddin. W, and Joan. 2006. Effects of Nest Depth, Shading, and Metabolic Heating on Nest Temperatures in Sea Turtle Hatcheries. Chelonian Conservation and Bioloogy 5.2 Malaysia. 210-215.

Mulyani. L. 2006. Studi Perbandingan Tingkat Keberhasilan Penetasan Telur Penyu Lekang (Lepidochelys olivacea) pada Penetasan Alami dan Buatan di Ngagelan Alas Purwo, Banyuwangi, Jawa Timur. Skripsi. Institut Pertanian Bogor. Bogor. Hal. 24-52

Satriadi, A, Esti R dan Nurul. A. 2004. Identifikasi Penyu dan Studi Karakteristik Fisik Habitat Penelurannya di Pantai Samas, Kabupaten Bantul, Yogyakarta. Jurusan Ilmu Kelautan, Fakultas Perikanan dan Ilmu Kelautan, Universitas Diponegoro, Semarang. ISSN 0853 - 7291. Vol. 8 (2) : 69 - 75

Yustina, Suwondo, Arnentis, dan Yuspen Hendri, 2004. Analisis Distribusi Sarang Penyu Hijau (Chelonia mydas) di Pulau Jemur Riau. Laboratorium Zoologi Jurusan PMIPA FKIP. Program Studi Pendidikan Biologi FKIP Universitas Riau. Pekanbaru. Jurnal Biogenesis Vol. 1(1): 31-36, 2004. ISSN : 1829-5460 